\title{
Risk Factors for the Development of the Disease in Antiphospholipid Antibodies Carriers: A Long-term Follow-up Study
}

\author{
Rosalía Demetrio Pablo ${ }^{1}$ (]) Pedro Muñoz Cacho ${ }^{2} \cdot$ Marcos López-Hoyos ${ }^{3,6} \cdot$ Vanesa Calvo-Río ${ }^{4}$. \\ Leyre Riancho-Zarrabeitia ${ }^{5}$ Víctor M. Martínez-Taboada ${ }^{4,6}$
}

Accepted: 17 May 2021 / Published online: 3 July 2021

(c) The Author(s) 2021

\begin{abstract}
The natural history of antiphospholipid antibodies (aPL) carriers is not well-established. The objectives of the present study were (a) to study the probability of developing clinical criteria of antiphospholipid syndrome (APS), (b) to identify potential risk factors for developing thrombosis and/or obstetric complications, (c) to study the association between the antibody profile and development of APS, and (d) to determine the efficacy of primary prophylaxis. We retrospectively analyzed 138 subjects with positive aPL who did not fulfill clinical criteria for APS. The mean follow-up time was $138 \pm 63.0$ months. Thirteen patients (9.4\%) developed thrombosis after an average period of $73.0 \pm 48.0$ months. Independent risk factors for thrombosis were smoking, hypertension, thrombocytopenia, and triple aPL positivity. Low-dose acetyl salicylic acid did not prevent thrombotic events. A total of 28 obstetric complications were detected in 92 pregnancies. During the follow-up, only two women developed obstetric APS. Prophylactic treatment in pregnant women was associated with a better outcome in the prevention of early abortions. The thrombosis rate in patients with positive aPL who do not meet diagnostic criteria for APS is $0.82 / 100$ patients-year. Smoking, hypertension, thrombocytopenia, and the aPL profile are independent risk factors for the development of thrombosis in aPL carriers. Although the incidence of obstetric complications in this population is high (31.6\%), only a few of them meet APS criteria. In these women, prophylactic treatment might be effective in preventing early abortions.
\end{abstract}

Keywords Antiphospholipid syndrome · Antiphospholipid antibodies · Thrombosis · Abortion · Primary prophylaxis

\section{Introduction}

Antiphospholipid syndrome (APS) is an acquired immune disorder defined by the presence of thrombosis and/or pregnancy morbidity along with positive antiphospholipid antibodies

Pedro Muñoz Cacho

pedro.munoz@scsalud.es

1 Servicio de Oftalmología, Hospital Universitario Marqués de Valdecilla, Cantabria, Spain

2 Gerencia de Atención Primaria IDIVAL, Servicio Cántabro de Salud, Cantabria, Spain

3 Servicio de Inmunología, Hospital Universitario Marqués de Valdecilla, Cantabria, Spain

4 Servicio de Reumatología, Hospital Universitario Marqués de Valdecilla IDIVAL, Cantabria, Spain

5 Sección de Reumatología, Hospital de Sierrallana, Cantabria, Spain

6 Facultad de Medicina, Universidad de Cantabria, Santander, Spain
(aPL), such as anticardiolipin antibodies (aCL), anti beta 2 glycoprotein antibodies (AB2GPI), and lupus anticoagulant (LA) [1]. The APS diagnosis requires both clinical (thrombosis and/or obstetric complications) and analytical evidence (confirmed presence of aPL). This is stated in the Sapporo international consensus [1], and later revised in Sydney [2].

The estimated incidence of aPL carriers in the general population is 5\% [3]. Recently, a higher incidence of antiphospholipid antibodies, especially antibodies not included in the classification criteria, has been described in the general population and related with subclinical arteriosclerosis [4].

The thrombosis rates in these patients are different according to the studied populations. Thrombosis rates of $3.8 \%$ have been reported in systemic lupus erythematosus (SLE) with positive aPL [5]. The annual incidence of thrombosis in patients with positive aPL antibodies but without history of thrombosis or obstetric manifestations is different between the reported studies, ranging from 0 , in patients without associated disorders [6], to 1.3-2.8/100 patients-year, in studies that mix healthy population with SLE and other autoimmune diseases [7, 8]. Rates of 7.4/100 
patient-years have been reported in women with recurrent abortions [5, 9]. Supplementary Table 1 summarizes the main studies published on this subject [5-8, 10-17].

Several predictive factors for thrombosis in patients with analytical but no clinical criteria for APS have been described. Among them, male gender [8], previous thrombosis [7, 8], smoking [10], hypertension [11], and SLE [18] are the most frequently cited. At the analytical level, LA has been the antibody most strongly associated with thrombosis [19]. Other authors have also found association with aCL $\operatorname{IgG}[7,11]$ or with AB2GPI [8]. On the other hand, some authors have also found an increased risk of thrombosis in patients without clinical APS but with multiple positivity for the different aPL [10, 11].

There is no consensus regarding the aPL profile that better predicts the obstetric complications. Both LA and aCL have been reported in the literature by different authors. Opatrny et al. [20] reported a meta-analysis to measure the strength of association between recurrent fetal loss and the presence of aPL in women without autoimmune diseases. They concluded that LA was the antibody most strongly associated with recurrent fetal loss. Lockshin et al. [21], in a multicenter prospective PROMISSE study, found an increased risk of fetal loss in patients with thrombosis or SLE history and positive LA.

In relation to the primary prophylaxis of these patients, the debate is still opened. There is consensus to treat SLE patients with acetyl salicylic acid (ASA) at low doses to prevent arterial or venous thrombosis [22]. However, this is not clear in asymptomatic patients without associated diseases. Preventive treatment of obstetric events is supported by the use of ASA and heparin as secondary prophylaxis [23], but in primary prophylaxis, there is a lack of consensus.

In the present study, we aimed to analyze the incidence of thrombosis and obstetric complications in patients with positive serology without a clinical criterion of APS, the potential risk factors for developing clinical APS, and analyzing the role of the autoantibody profile and primary prophylaxis in the development of clinical manifestations of the disease.

\section{Material and Methods}

\section{Selection of Patients}

Retrospective data were collected from 138 patients without clinical criteria for APS but with confirmed positive serology (aCL and/or AB2GPI) at medium or high titers separated by a minimum of 12 weeks [2]. Patients were selected from the database of the Immunology Division of a tertiary hospital. A total of 1200 clinical records from aPL positive patients between 1999 and 2004 were reviewed. Exclusion criteria included patients with a clinical diagnosis of APS, absence of confirmation for serology, and low titers of aPL. LA data were available in 89 of these patients. The study was carried out in accordance with the Declaration of Helsinki and approved by the Ethical Committee of Clinical Research of Cantabria.

\section{Clinical Data}

The clinical data of the patients were obtained through a retrospective review of the medical history according to a predefined protocol. Demographic data (age and sex), cardiovascular risk factors (hypertension, diabetes, dyslipidemia, smoking), associated diseases, presence of aPL (aCL IgG/M, AB2GPI $\mathrm{IgG} / \mathrm{M}, \mathrm{LA})$, development of thrombosis, and/or obstetric disease, as well as the treatment received, were recorded.

\section{Determination of aPL}

The immunology laboratory quantifies by commercial enzyme immunoassay in solid phase (ELISA) the presence of the following antibodies and isotypes of aPL: aCL of the IgG and IgM isotype and $\mathrm{AB} 2 \mathrm{GPI}$ of the $\mathrm{IgG}$ and $\mathrm{IgM}$ isotype. The results are reported as quantitative and semiquantitative. Thus, the $\mathrm{aCL}$ are quantified in GPL (aCL IgG) or MPL (IgM aCL) according to the standard curve that is constructed in each test with 5 dilution points of the Harris/Sapporo standards. AB2GPI is quantified as $\mathrm{U} / \mathrm{ml}$. The criteria recommended by the International Society of Thrombosis and Hemostasis (ISTH) Scientific and Standardization Committee (ISTH) for the standardization of LA/APA were applied for the characterization of LA [24].

\section{Statistical Analysis}

A database was generated using the SPSS statistics 20. The qualitative variables have been described using the percentages. In the quantitative variables, the data were adjusted to the normal distribution using the Kolmogorov-Smirnov test, using, depending on the case, the arithmetic mean and the standard deviation or the median and the interquartile range. In the hypothesis tests, we used chi-square test or Fisher exact test for differences between groups in qualitative variables. To assess differences in numerical variables between 2 groups, we used the Student $t$ test or the Mann-Whitney test, according to the adjustment of the variables to the normal distribution. In order to quantify the strength of the association, the odds ratio (OR) was used with its $95 \%$ confidence interval. To estimate the independent effect of the different variables on categorical dichotomous variables, we used logistic regression with the "enter" method.

The incidence rate of first case on thrombosis was calculated and expressed as the number of thrombosis per 100 patients-year. Logistic regression analysis was used to evaluate the independent effect of triple positivity and thrombocytopenia on thrombosis risk, controlling for established cardiovascular risk factors (smoking, high blood pressure, and dyslipidemia). To evaluate the predictive capacity of the 
Table 1 Comparison between aPL carriers with and without thrombosis

\begin{tabular}{llll}
\hline & \multicolumn{2}{l}{ Thrombosis } & \\
\cline { 2 - 4 } & $\begin{array}{l}\text { No } \\
\text { No. }(\%)\end{array}$ & $\begin{array}{l}\text { Yes } \\
\text { No. }(\%)\end{array}$ & $p$ \\
\hline Patients & $125(90.6)$ & $13(9.4)$ & \\
Female & $109(87.2)$ & $10(77)$ & 0.306 \\
Age, years(mean \pm SD) & $40.9 \pm 16.3$ & $45.5 \pm 4.9$ & 0.335 \\
Associated diseases: & & & \\
$\quad$ SLE & $23(18.3)$ & $4(30.8)$ & 0.285 \\
CVRF & & & \\
$\quad$ Diabetes & $2(1.6)$ & $0(0)$ & 0.646 \\
$\quad$ Smokers & $29(23.2)$ & $8(61.5)$ & 0.003 \\
$\quad$ HBP & $19(15.3)$ & $7(53.8)$ & 0.001 \\
$\quad$ Dyslipidemia & $7(5.6)$ & $5(38.5)$ & 0.001 \\
\hline
\end{tabular}

No. number of patients, $S D$ standard deviation, $p$ statistical significance, $S L E$ systemic lupus erythematosus, $C V R F$ cardiovascular risk factors, $H B P$ high blood pressure

different models, we used the area under the curve (AUC), and we compared the curves by the DeLong test. In addition, a backward conditional model was developed.

A Kaplan-Meier survival analysis and the log-rank test were carried out to analyze the cumulative incidence of events in the different groups of patients. Because methodological heterogeneity between studies was anticipated, a random-effects (DerSimonian and Laird) model was used for pooling the data. The between-study heterogeneity was assessed by using $I^{2}$ statistic. $I^{2}$ values of $25 \%, 50 \%$, and $75 \%$ were considered to represent low, moderate, and high heterogeneity, respectively [25]. The possibility of publication bias was assessed statistically by using Egger's tests [26] and visual inspection of funnel plots. The influence of a potential publication bias was explored by using the Duval and Tweedie "trim and fill" procedure [27]. These methods were used for the purpose of sensitivity analysis [28].

The IBM SPSS 25 (IBM Corp. Released 2017. IBM SPSS Statistics for Windows, Version 25.0. Armonk, NY: IBM Corp.), MedCalc Statistical Software version 18.9 (MedCalc Software bvba, Ostend, Belgium; http://www.medcalc.org; 2018), and Comprehensive Meta-Analysis software version 2.2.064 (Biostat, Englewood, NJ) were used for statistical analyses.

\section{Results}

We analyzed 138 patients with positive serology for aPL (ACL, AB2GPI). Only patients with confirmed positive serology (aCL and/or AB2GPI) at medium or high titers separated by a minimum of 12 weeks [2] were included. One hundred and nineteen were women, and 19 were men. The mean age of the total sample was $41.36 \pm 16.1$ years. We analyzed the incidence of vascular and obstetric events during a mean follow-up of $138 \pm 63$ months (Table1).

\section{Analysis of Thrombotic Events in aPL Carriers}

During the study period, thirteen patients (9.4\%) developed thrombosis. The global thrombosis rate was $0.82 / 100$ patientsyear. The highest thrombosis rate was found in triple aPLpositive carriers (3.0/100 patients-year). The mean time to the thrombotic episode was $73.0 \pm 48.0$ months. Figure 1 shows
Fig. 1 Thrombotic event-free survival curve. The figure shows the thrombosis-free survival during the follow-up. The incidence rate is 0.82 thrombosis per 100 patients-year (13 events/1591 total person-year). A relatively uniform incidence is seen within the first 10 years of follow-up. It should be noted that after the seventh year, the number of people under followup is $<100$

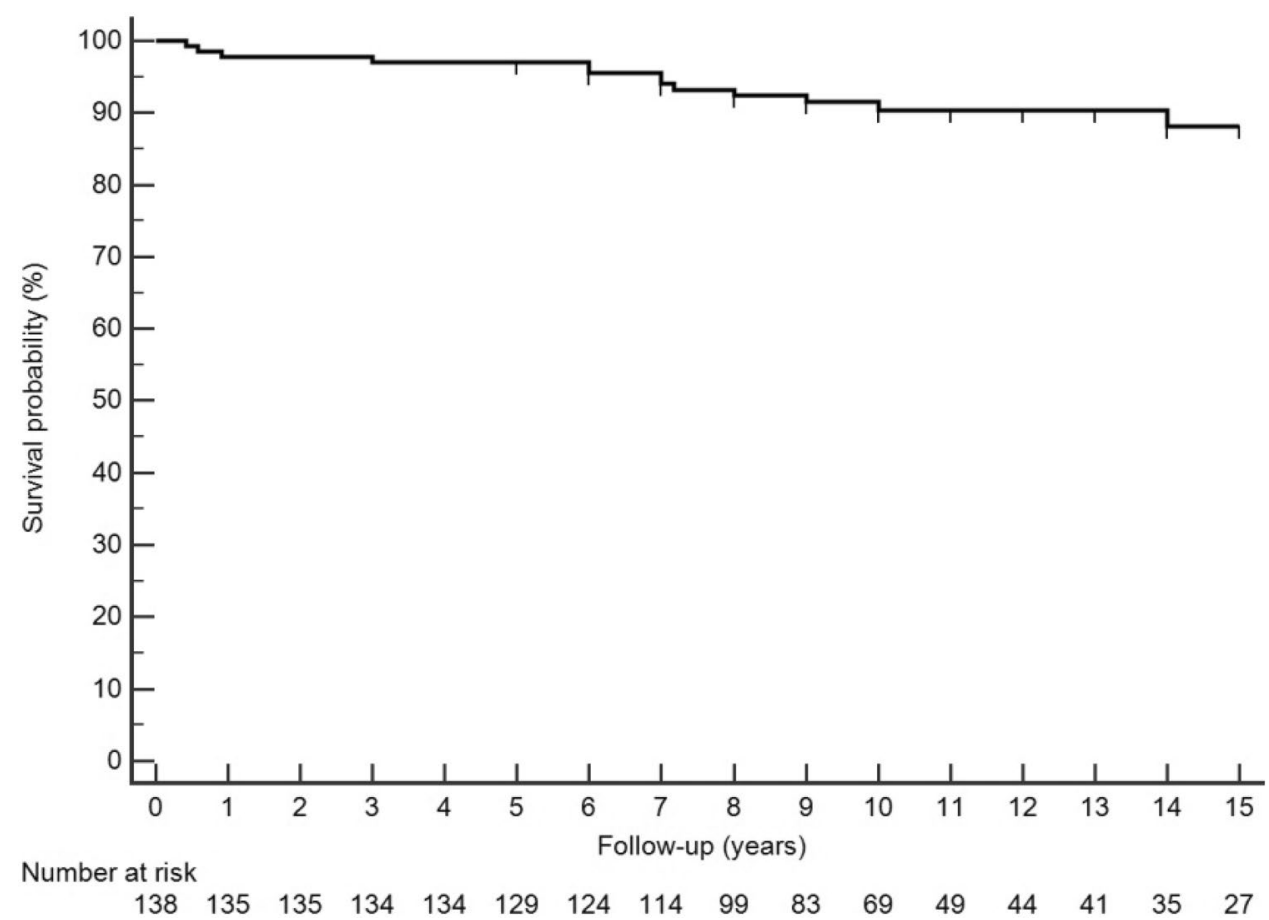


Table 2 Frequency and odds ratio (OR) for thrombosis within the different serologic subgroups in aPL carriers. The OR were calculated taking as a reference category those patients positive only for aCL $\mathrm{IgG}$

\begin{tabular}{lllll}
\hline aPL serology & No. of patients & $\begin{array}{l}\text { No. of } \\
\text { thrombosis } \\
(\%)\end{array}$ & OR & $p$ \\
\hline $\begin{array}{l}\text { aCL IgG (reference } \\
\text { category) }\end{array}$ & 38 & $2(5.3)$ & & \\
aCL Ig M & 30 & $2(6.7)$ & 1.29 & 0.807 \\
aCL IgG + aCL IgM & 9 & $2(22.2)$ & 5.14 & 0.130 \\
AB2GPI IgG & 7 & $1(14.3)$ & 3.00 & 0.399 \\
AB2GPI IgM & 3 & $0(0.0)$ & - & 0.999 \\
AB2GPI IgG + AB2GPI & 1 & $0(0.0)$ & - & 1.00 \\
IgG & & $1(7.7)$ & 1.50 & 0.749 \\
aCL+LA & 13 & $1(4.3)$ & 0.82 & 0.873 \\
aCL+AB2GPI & 23 & $4(30.8)$ & 8.00 & 0.027 \\
aCL+AB2GPI+LA & 13 & $0(0.0)$ & - & 1.00 \\
AB2GPI+LA & 1 & $13(9.4)$ & & \\
Total & 138 & & &
\end{tabular}

No. number, $a P L$ antiphospholipid antibodies, $a C L$ anticardiolipin antibodies, $A B 2 G P I$ antibeta 2 glycoprotein antibodies, $L A$ lupus anticoagulant

the thrombosis-free survival during the follow-up. Table 2 shows the main demographic characteristics, associated diseases, and classic vascular risk factors of patients who developed thrombosis versus those who did not. Cardiovascular risk factors, especially smoking, hypertension, and dyslipidemia, were significantly more frequent in patients who developed thrombosis. As previously reported [28], 17 of the 138 (12\%) patients in the present cohort had thrombocytopenia (platelet count $\leq 100,000 / \mu \mathrm{l})$. The risk of developing thrombocytopenia was higher in smokers (OR 2.8; $p=0.044$ ) and those with higher burden of aPL (OR 13.4; $p<0.001$ ). During the follow-up, 5 patients with thrombocytopenia (29.4\%) developed thrombosis (OR 5.9 [IC 95\% 1.7-20.9]; $p=0.003$ ). On the other hand, the presence triple aPL positivity (LA, aCL, AB2GPI) was associated with an increased risk for thrombosis (OR of 8.00, $p=0.027$ ) (Table 2).

The next step was to evaluate the predictive capacity of different models to predict the development of thrombotic events in aPL carriers. Table 3 summarizes the OR, $p$ value, and AUCs for the 7 models tested. Model 0 and the four-covariate models (M1, M2, and M3) have a very similar AUC, approximately 89\%. Model 6, which includes smoking, HBP, and thrombocytopenia, is the only one with three variables that achieves an AUC of $89 \%$. Although the difference in their respective AUCs was not significant $(p=0.311)$, thrombocytopenia predicts better the incidence of thrombosis than triple positivity (M5 vs. M6).
Table 3 Multivariate analysis including classic cardiovascular risk factors, triple positivity, and thrombocytopenia

\begin{tabular}{|c|c|c|c|}
\hline Model & OR $(95 \%$ CI $)$ & $p$ value & AUC (\%) \\
\hline M0 & & & 89.7 \\
\hline Smoking & $10.25(2.18-48.24)$ & 0.003 & \\
\hline HBP & $8.74(1.57-48.82)$ & 0.014 & \\
\hline Dyslipidemia & $2.87(0.53-15.47)$ & 0.220 & \\
\hline Triple positivity ${ }^{a}$ & $2.31(0.28-19.08)$ & 0.438 & \\
\hline Thrombocytopenia & $4.09(0.57-28.05)$ & 0.159 & \\
\hline M1 & & & 89.9 \\
\hline Smoking & $11.00(2.38-50.53)$ & 0.002 & \\
\hline HBP & $6.92(1.36-35.29)$ & 0.020 & \\
\hline Dyslipidemia & $3.63(0.71-18.52)$ & 0.121 & \\
\hline Triple positivity ${ }^{a}$ & $5.20(1.00-27.08)$ & 0.050 & \\
\hline \multicolumn{4}{|l|}{ M2 } \\
\hline Smoking & $10.12(2.19-46.80)$ & 0.003 & 89.1 \\
\hline HBP & $9.77(1.80-53.17)$ & 0.008 & \\
\hline Dyslipidemia & $2.73(0.52-14.25)$ & 0.233 & \\
\hline Thrombocytopenia & $6.29(1.27-31.02)$ & 0.024 & \\
\hline M3 & & & 89.1 \\
\hline Smoking & $11.69(2.55-53.54)$ & 0.002 & \\
\hline HBP & $13.03(2.66-63.72)$ & 0.002 & \\
\hline Triple positivity $^{\mathrm{a}}$ & $2.11(0.28-16.13)$ & 0.473 & \\
\hline Thrombocytopenia & $5.11(0.78-33.35)$ & 0.088 & \\
\hline M4 & & & 86.4 \\
\hline Smoking & $11.25(2.54-49.89)$ & 0.001 & \\
\hline HBP & $7.30(1.50-35.46)$ & 0.014 & \\
\hline Dyslipidemia & $3.67(0.77-17.57)$ & 0.103 & \\
\hline M5 & & & 86.2 \\
\hline Smoking & $12.38(2.78-55.26)$ & 0.001 & \\
\hline HBP & $10.64(2.37-47.71)$ & 0.002 & \\
\hline Triple positivity $^{\mathrm{a}}$ & $5.30(1.06-26.51)$ & 0.042 & \\
\hline M6 & & & 89.2 \\
\hline Smoking & $11.48(2.54-51.87)$ & 0.002 & \\
\hline HBP & $14.19(2.94-68.56)$ & 0.001 & \\
\hline Thrombocytopenia & $7.40(1.55-35.20)$ & 0.012 & \\
\hline
\end{tabular}

$O R$ odds ratio, $C I$ confidence interval, $A U C$ area under the curve, $H B P$ high blood pressure

${ }^{\text {a }}$ Single or double versus triple

The variables of M6 were selected using the backward conditional method with M0 (Supplementary Table 2).

Supplementary Table 3 shows the main characteristics of the 13 patients who developed thrombosis. Nine patients were taking ASA prior to the development of thrombosis. Of the 13 thrombotic events, 10 were arterial and 3 occurred in venous territory. Of the 138 patients, 103 received prophylaxis with ASA (100 mg/day). As shown in Fig. 2, aPL carriers on prophylactic treatment with lowdose ASA had a higher risk for thrombosis (hazard ratio 
Fig. 2 Kaplan-Meier thrombosisfree survival according to aspirin intake. There are no differences in the incidence of thrombosis during the first 7 years of follow-up between both groups. After this date, the differences are not significant $(p=0.393)$. AAS acetyl salicylic acid

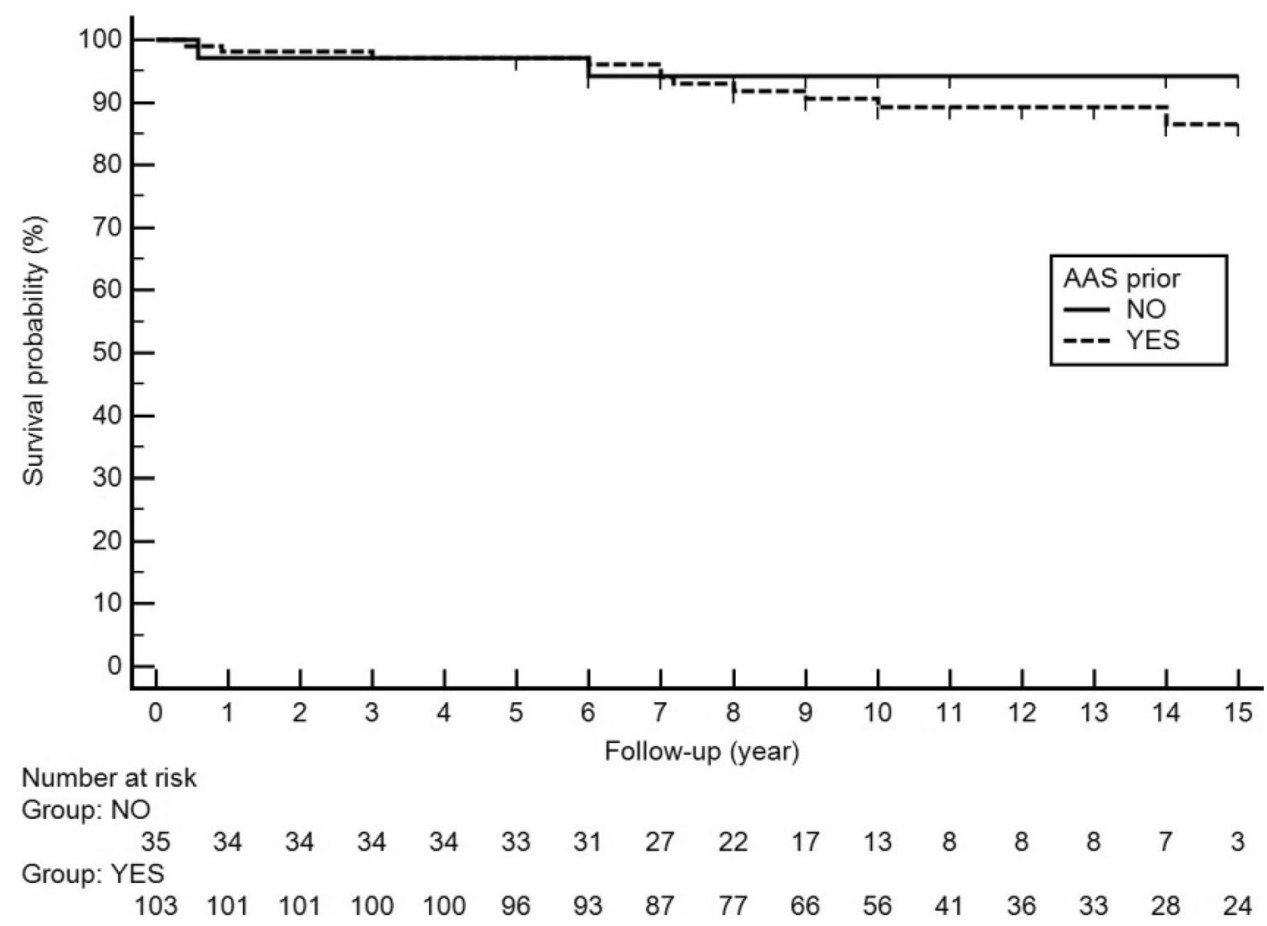

1.49 [95\% CI 0.33-6.79]), although this difference was not statistically significant $(p=0.393)$.

\section{Obstetric Events in Women with Positive aPL}

We analyzed 92 pregnancies in 39 women with positive aPL. LA data were available in 34 of the 39 women. Since many of the pregnancies occurred before aPL detection, we decided to carry out a second analysis of 38 pregnancies in 15 women who had a gestation after the positivity of the antibodies was detected. Only two patients evolved to obstetric APS (Supplementary Table 4) and none to thrombotic APS.

The results obtained with the two different analyses were as follows (Table 4):

Table 4 Description of obstetric complications in women after positive aPL versus pregnancies in women before and after positive aPL

\begin{tabular}{|c|c|c|c|c|}
\hline \multirow[b]{2}{*}{ Obstetric complication } & \multicolumn{2}{|c|}{$\begin{array}{l}\text { Pregnancies } \\
\text { after aPL+ } \\
(\text { No. }=38)\end{array}$} & \multicolumn{2}{|c|}{$\begin{array}{l}\text { Pregnancies } \\
\text { before and } \\
\text { after aPL+ } \\
(\text { No. }=92)\end{array}$} \\
\hline & No. & $\%$ & No. & $\%$ \\
\hline Early pregnancy loss $(<10$ weeks $)$ & 8 & 21 & 21 & 22.8 \\
\hline Fetal loss $>10$ weeks & 1 & 2.6 & 1 & 1.1 \\
\hline Preterm birth $<34$ weeks & 1 & 2.6 & 1 & 1.1 \\
\hline Intrauterine growth restriction & 2 & 5.3 & 3 & 3.3 \\
\hline Preeclampsia & 0 & 0 & 2 & 2.2 \\
\hline Normal pregnancy & 26 & 68.4 & 64 & 69.6 \\
\hline
\end{tabular}

No. number, $a P L$ antiphospholipid antibodies
1. Results of 92 pregnancies in 39 women before and after presenting positive serology for aPL. Overall, two-thirds of aPL carriers ended in a normal pregnancy. A total of 28 obstetric complications were detected in 26 of the 92 pregnancies. The mean age of pregnant women at delivery was $29.86 \pm 5.8$ years. The gestational age of the newborn presented an average of $38.2 \pm 1.77$ weeks, and the mean birth weight was $3108 \pm 482.5 \mathrm{~g}$. The mean Apgar Score was $8.66 \pm 1.1$. Only 8 out of the 39 women received treatment with ASA (100 mg/day), and ASA was associated with low weight molecular heparin (LWMH) in three of them. We did not obtain significant differences when we evaluated the influence of treatment on the total obstetric complications. However, prophylactic treatment was associated with a better outcome in the prevention of early abortions ( $<10$ weeks) with an OR of 0.12 (95\% CI 0.02 to $0.95, p=0.019)$.

2. Results of 38 pregnancies in 15 women after positive serology for aPL. A total of 12 obstetric complications were detected among the 38 pregnancies: 8 early abortions, one fetal loss, one preterm birth, and two IUGR. Six women received treatment with ASA (100 mg/day), together with LMWH in 3 of them. In this scenario, patients on prophylactic treatment showed a significant reduction on the total obstetric complications, with an OR of 0.15 (95\% CI $0.02-0.85 ; p=0.021)$. In agreement with the previous analysis, prophylactic treatment was also effective in the prevention of early abortions ( $<10$ weeks) with an OR of 0.40 (95\% CI 0.26-0.62, $p=0.003$ ) 


\section{Discussion}

The clinical course of patients with positive aPL serology who do not meet clinical criteria for APS has not been clearly established. Supplementary Table 1 reflects the variability in thrombosis rates reported by the different authors [5-8, 10-17]. As shown in Fig. 3, the thrombosis rate was highly variable depending on the different studies analyzed. Pooled random effect estimate was 1.7 thrombosis per 100 patientsyear (IC 1.1-2.2). The present study showed a global thrombosis rate of $0.82 / 100$ patients-year, which is located in the lower range when compared with other studies. However, when we analyzed only patients with triple positivity, the thrombosis rate increased up to 3.0/100 patients-year. In only two studies, Girón-González et al. [6] and Pengo et al. [11], the limits were not within the combined estimation (CI 1.1-2.2). As shown in Supplementary Fig. 1, and although it is not possible to find symmetry in the representation of the incidence rate, because incidences lower than $0 \%$ are not possible (shaded area); there is a lack of studies on the left side, corresponding to studies with low sample numbers and low incidence rates of thrombotic events. This means that there is a certain asymmetry with respect to the number of studies with an incidence of $0 \%$ or very close to it. The Egger's test of the intercept was significant $(p<0.0001)$, suggesting again the existence of asymmetry. Using Duval and Tweedie "trim and fill" method, under the random effect model, the recomputed global estimation of the incident rate was 0.78 thrombosis per 100 patients-year (CI 0.24-1.32), a number that is clearly lower that the obtained directly from the studies (1.7 thrombosis per 100 patients-year), and very similar to the results of the present study ( 0.82 thrombosis per 100 patients-year). Nevertheless, the results of this metaanalysis should be taken with caution because of the high heterogeneity $\left(I^{2}=86.7 \%\right)$ of the different studies. Several factors might explain these diverging results-the follow-up time, the proportion of patients with associated diseases (especially SLE), the aPL profile, and the different therapeutic (primary prophylaxis) approaches. Furthermore, the influence of persistently positive serology, although relevant [30-32], has not been addressed in the majority of the studies.

Current evidence supports the theory that the presence of aPL is not the only risk factor necessary for developing thrombosis [33]. The coexistence of other factors, and more specifically classic cardiovascular risk factors, could act as triggers [10, 11]. In our study, smoking, hypertension, and dyslipidemia were identified as risk factors for thrombosis in this aPL carrier population. These findings support the concept that primary prophylaxis in aPL carriers should start by a proper treatment and correction of cardiovascular risk factors.

Thrombocytopenia is a non-criteria manifestation of APS. As recently reviewed [29], thrombocytopenia might be associated with a higher risk of thrombosis in aPL carriers, and also in patients with low aPL titters [17]. Although the difference in their respective AUCs was not significant $(p=0.311)$, thrombocytopenia better predicts the incidence of thrombosis than triple positivity (M5 vs. M6). These results might be explained because the linear association of thrombocytopenia with the burden of aPL [29].
Fig. 3 Forest plots of the incident rate of thrombosis per 100 patients-year using a randomeffects analysis. The squares represent study-specific incident rate (the square sizes are proportional to the weight of each study in the overall estimate); the horizontal lines represent 95\% confidence intervals (CI), and the diamond represents the overall incident rate estimate with $95 \% \mathrm{Cl}$

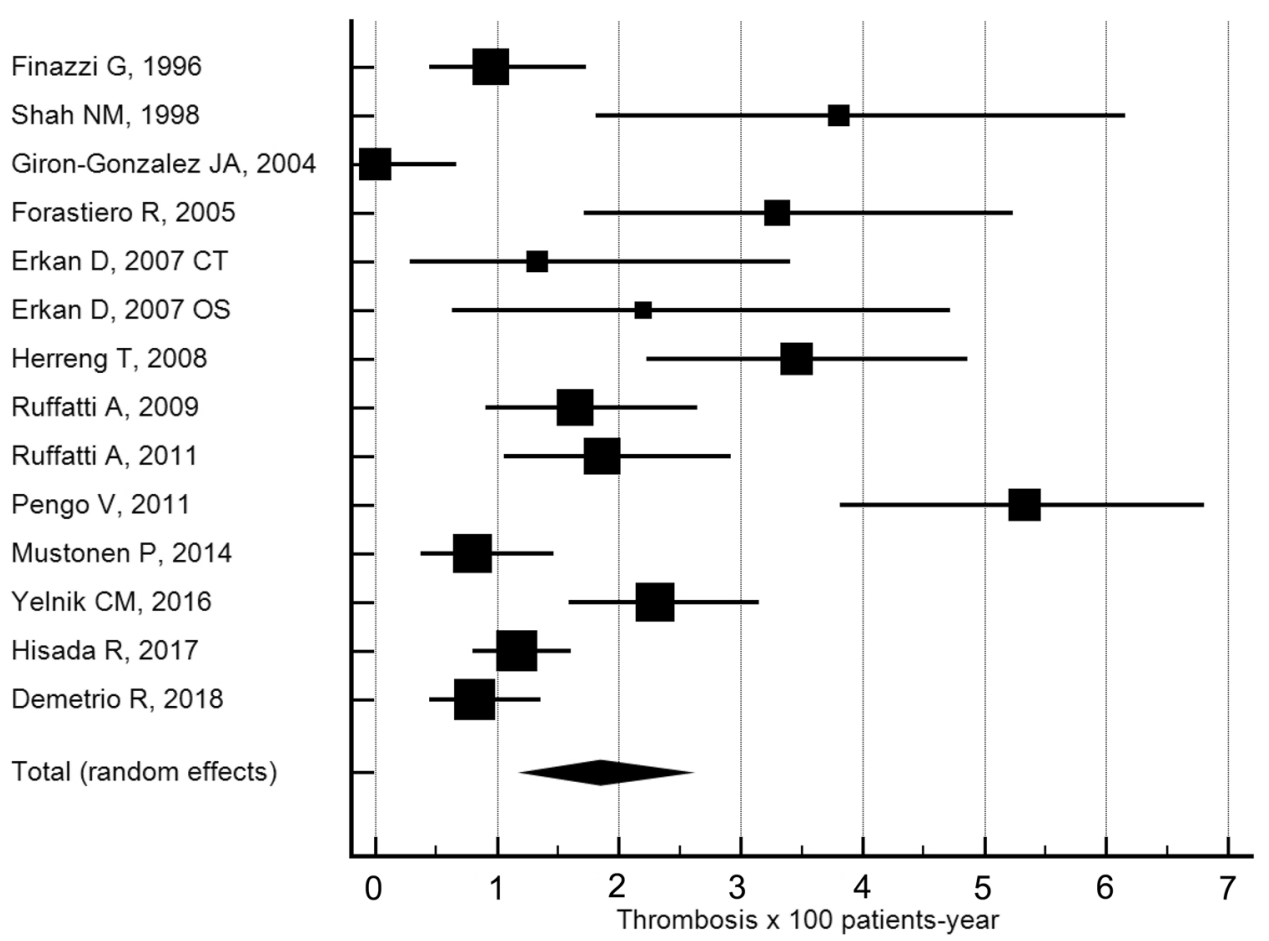


Our study has the peculiarity of studying patients who were asymptomatic or who did not meet disease criteria, with a sample size of 138 patients and a mean follow-up of $138 \pm 63$ months. We obtained, as did other authors [10, 11], a statistically significant increase in risk among those who were positive for the three types of antibodies (LA, aCL, and AB2GPI), with an OR of 7.3 (95\% CI 1.9-28.5, $p=0.004)$. The only published cohort without associated autoimmune diseases was published by Girón et al. [6], where none developed thrombosis probably because of the short follow-up (36 months). In our study, the mean time to the thrombotic event was $73.0 \pm 48.0$ months.

Regarding treatment, there is general agreement to treat APS that have had thrombosis or recurrent fetal loss to prevent new events [23]. However, it is unclear what to do in those patients with incidentally positive serology and no history of thrombosis or obstetric morbidity. It has only been studied more extensively in patients with SLE, where primary prophylaxis of these patients is accepted [22]. The different studies on primary thromboprophylaxis in patients with asymptomatic aPL positive patients are shown in Supplementary Table 1 . There is only one clinical trial that addressed this issue which was carried out by Erkan et al. (APLASA study) [14], concluding that ASA did not protect against thrombosis. However, the limited number of patients, the short follow-up, and the low rate of thrombosis made it difficult to draw definitive conclusions. In the present study, ASA did not show a protective role in these patients (Fig. 2). In fact, aPL carriers treated with ASA showed a non-significant increase in the number of thrombotic events. This surprising finding might be related with the concept of confounding by indication. Furthermore, and as stated before, the lack of protective effect might be related to several factors, including the dose of ASA [34]. To clearly establish the role of primary prophylaxis in aPL carriers, it would be necessary to act on those modifiable risk factors, especially on all those related to cardiovascular risk. On the other hand, in those patients with associated independent risk factors, or with an elevated GAPSS score, primary prophylaxis should be considered. An international multicenter effort should address which is the best primary prophylaxis approach in aPL carriers stratified according to the risk of thrombosis.

The literature on obstetric outcome in patients with positive aPL who do not meet the clinical criteria of APS is scarce. Most published studies mix asymptomatic patients with patients with APS, SLE, and other autoimmune diseases. We have found few articles that analyze patients that meet the analytical but non-clinical criteria of APS. Chauleur et al. [35] analyzed the evolution of a second pregnancy in women with a previous abortion $<10$ weeks and with positive aPL who did not meet APS criteria. LA and IgM aCL were associated with abortions. The aCL IgM and IgG were associated with late complications. The authors did not recommend screening for aPL in all patients with an early abortion because $70 \%$ of second pregnancies were successfully completed. Girón et al. [6] did not find any obstetric complications in a prospective study of a cohort of 178 patients with non-clinical APS. Pengo et al. [11] prospectively studied 104 aPL positive patients and obtained more obstetric morbidity among those with positivity for the 3 types of aPL. May Chi Soh et al. [36] retrospectively studied 73 patients with positive aPL without clinical disease and compared them with 73 patients with defined APS and with 292 negative controls for aPL. They concluded that those with defined APS had 4 times more risk of obstetric complications, with no differences between asymptomatic aPL patients and controls. In a prospective study by Mustonen et al. [10], 20\% of the 119 patients developed obstetric complications (four of them meeting criteria for APS). Among our patients, only two patients developed obstetric APS. We did not observe any statistically significant association between the antibody profile and the clinical phenotype of these patients, although the results may be limited by the number of patients included.

Regarding the treatment of obstetric APS, although a Cochrane review in 2005 [37] concluded that the management of these patients remained uncertain, the use of ASA, associated or not, with LWMH is generally recommended [38]. The opinion of different authors about the treatment of pregnancy in asymptomatic women with positive aPL is also variable. An observational study by Del Ross et al. [39] reviewed 139 pregnancies in 114 women with aPL who did not meet clinical criteria for APS. There were no significant differences in treatment. However, they concluded that its use could be justified because pregnancy itself and the presence of aPL is additional risk factors for thrombosis. Amengual et al. [40] published a meta-analysis with a review of the literature on primary prophylaxis to prevent obstetric complications in asymptomatic women with aPL. They concluded that there is no sufficient evidence to treat these patients in the absence of other risk factors. In our study, however, we found a protection with prophylactic treatment with ASA (100 mg/day), and in some cases associated with $\mathrm{LWMH}$, in the prevention of early miscarriages. However, two cases of IUGR and one preterm delivery were observed in three of the pregnancies, all in treated patients. These findings could be explained due to early obstetric morbidity prevention with a higher rate of late complications. More prospective studies with larger sample sizes are necessary to corroborate these observations.

In summary, we conclude that smoking, hypertension, thrombocytopenia, and the number of positive aPL are independent risk factors for thrombosis in patients with aPL positive without clinical criteria for APS. In these patients, it seems that ASA has a limited protective role. At the obstetric level, we cannot draw conclusions about the aPL profile, probably because of the limited sample size. However, we observed that prophylactic treatment might be effective in the prevention of early abortions, with a higher rate of live births. 
Supplementary Information The online version contains supplementary material available at https://doi.org/10.1007/s12016-021-08862-5.

Funding Open Access funding provided thanks to the CRUE-CSIC agreement with Springer Nature.

\section{Declarations}

Conflict of Interest The authors have declared no competing interests.

Open Access This article is licensed under a Creative Commons Attribution 4.0 International License, which permits use, sharing, adaptation, distribution and reproduction in any medium or format, as long as you give appropriate credit to the original author(s) and the source, provide a link to the Creative Commons licence, and indicate if changes were made. The images or other third party material in this article are included in the article's Creative Commons licence, unless indicated otherwise in a credit line to the material. If material is not included in the article's Creative Commons licence and your intended use is not permitted by statutory regulation or exceeds the permitted use, you will need to obtain permission directly from the copyright holder. To view a copy of this licence, visit http://creativecommons.org/licenses/by/4.0/.

\section{References}

1. Wilson WA, Gharavi AE, Koike T, Lockshin MD, Branch DW, Piette JC et al (1999) International consensus statement on preliminary classification criteria for definite antiphospholipid síndrome: report of an international workshop. Arthritis Rheum 42:1309-1311

2. Miyakis S, Lockshin MD, Atsumi T, Branch DW, Brey RL, Cervera $R$ et al (2006) International consensus statement on an update of the classification criteria for definite antiphospholipid síndrome (APS). J Thromb Haemost 4:295-306

3. Stepien K, Nowak K, Wypasek E, Zalewski J, Undas A (2019) High prevalence of inherited thrombophilia and antiphospholipid syndrome in myocardial infarction with non-obstructive coronary arteries: comparison with cryptogenic stroke. Int J Cardiol 290:1-6

4. Selmi C, De Santis M, Battezzati PM, Generali E, Lari SA, Ceribelli A et al (2020) Anti-phospholipid antibody prevalence and association with subclinical atherosclerosis and atherothrombosis in the general population. Int J Cardiol 300:209-213

5. Shah NM, Khamashta MA, Atsumi T, Hugues GR (1998) Outcome patients with anticardiolipin antibodies: a 10 follow-up of 52 patients. Lupus 7:3-6

6. Giron-Gonzalez JA, Garcia del Rio E, Rodriguez C, RodriguezMartorell J, Serrano A (2004) Antiphospholipid syndrome and asymptomatic carriers of antiphospholipid antibody: prospective analysis of 404 individuals. J Rheumatol 31:1560-1567

7. Finazzi G, Brancaccio V, Moia M, Ciavarella N, Mazzucconi MG, Schinco PC et al (1996) Natural history and risk factors for thrombosis in 360 patients with antiphospholipid antibodies: a four-year prospective sudy from the Italian Registry. Am J Med 100:530-536

8. Forastiero R, Martinuzzo M, Pombo G, Puente D, Rossi A, Celebrin L et al (2005) A prospective study of antibodies to B2-glycoprotein I and prothrombin, a risk of thrombosis. J Thromb Haemost 3:1231-1238

9. Erkan D, Merrill JT, Yazzici Y, Sammaritano L, Buyon JP, Lockshin MD et al (2001) High thrombosis rate after fetal loss in antiphospholipid syndrome: effective prophylaxis with aspirin. Arthritis Rheum 44:1466-1467

10. Mustonen P, Lehtonen KV, Javela K, Puurunen M (2014) Persistent antiphospholipid antibody (aPL) in asymptomatic carriers as a risk factor for future thrombotic events: a nationwide prospective study. Lupus 23:1468-1476

11. Pengo V, Ruffatti A, Legnani C, Testa S, Fierro T, Marongiu F et al (2011) Incidence of a first thromboembolic event in asymptomatic carriers of high-risk antiphospholipid antibody profile: a multicentre prospective study. Blood 118:4714-4718

12. Ruffati A, Del Ross T, Ciprian M, Nuzzo M, Rampudda M, Bertero MT et al (2009) Risk factors for a first thrombotic event in antiphospholipid antibody carriers. A multicenter, retrospective follow-up study. Ann Rheum Dis 68:397-399

13. Ruffati A, Del Ross T, Ciprian M, Bertero MT, Sciascia S, Scarpato $S$ et al (2011) Risk factors for a first thrombotic event in antiphospholipid antibody carriers: a prospective multicenter follow-up study. Ann Rheum Dis 70:1083-1086

14. Erkan D, Harrison MJ, Levy R, Peterson M, Petri M, Sammaritano L et al (2007) Aspirin for primary thrombosis prevention in the antiphospholipid syndrome: a randomized, double-blind, placebo controlled trial in asymptomatic antiphospholipid antibody-positive individuals. Arthritis Rheum 56:2382-2391

15. Hereng T, Lambert M, Hachulla E, Samor M, Dubucquoi S, Caron $\mathrm{C}$ et al (2008) Influence of aspirin on the clinical outcomes of 103 antiphospholipid antibodies-positive patients. Lupus 17:11-15

16. Yelnik CM, Urbanski G, Drumez E, Sobanski V, Maillard H, Lanteri A et al (2017) Persistent triple antiphospholipid antibody positivity as a strong risk factor of first thrombosis, in a longterm follow-up study of patients without history of thrombosis or obstetrical morbidity. Lupus 26:163-169

17. Hisada R, Kato M, Sugawara E, Fujieda Y, Oku K, Bohgaki T et al (2017) Thrombotic risk stratification by platelet count in patients with antiphospholipid antibodies: a longitudinal study. J Thromb Haemost 15:1782-1787

18. Sciascia S, Cosseddu D, Montaruli B, Kuzenko A, Bertero MT (2011) Risk scale for the diagnosis os antiphospholipid syndrome. Ann Rheum Dis 70:1517-1518

19. Sciascia S, Sanna G, Murru V, Roccatello D, Khamashta MA, Bertolaccini ML (2015) The global anti-phospholipid syndrome score in primary APS. Rheumatology 54:134-138

20. Opatrny L, David M, Kahn SR, Shrier I, Rey E (2006) Association between antiphospholipid antibodies and recurrent fetal loss in women without autoinmune disease: a metaanalysis. J Rheumatol 33:2214-2221

21. Lockshin MD, Kim M, Laskin CA, Guerra M, Branch DW, Merrill J et al (2012) Lupus anticoagulant, but not anticardiolipin antibody, predicts adverse pregnancy outcome in patients with antiphospholipid antibodies. Arthritis Rheum 64:2311-2318

22. Cuadrado MJ, Bertolaccini ML, Seed PT, Tektonidou MG, Aguirre A, Mico L et al (2014) Low-dose aspirin vs low dose aspirin plus lowintensity warfarin in thromboprophylaxis: a prospective, multicentre, randomized, open, controlled trial in patients positive for antiphospholipid antibodies (ALIWAPAS). Rheumatology (Oxford) 53:201-202

23. Ruiz-Irastorza G, Hunt BT, Khamashta MA (2007) A systematic review of secondary thromboprophylaxis in patients with antiphospholipid antibodies. Arthritis Rheum 57:1487-1495

24. Ortel TL (2012) Laboratory diagnosis of the lupus anticoagulant. Curr Rheumatol Rep 14:64-70

25. Higgins JP, Thompson SG (2002) Quantifying heterogeneity in a meta-analysis. Stat Med 21:1539-1558

26. Egger M, Davey Smith G, Schneider M, Minder C (1997) Bias in meta-analysis detected by a simple, graphical test. BMJ 315:629-634

27. Duval S, Tweedie R (2000) Trim and fill: A simple funnel-plot-based method of testing and adjusting for publication bias in meta-analysis. Biometrics 56:455-463

28. Murad MH, Chu H, Lin L, Wang Z (2018) The effect of publication bias magnitude and direction on the certainty in evidence. BMJ Evid Based Med 23:84-86 
29. Demetrio-Pablo R, Muñoz P, López-Hoyos M, Calvo V, Riancho L, Martínez-Taboada VM (2017) Thrombocytopenia as a thrombotic risk factor in patients with antiphospholipid antibodies without disease criteria. Med Clin (Barc) 148:394-400

30. Riancho-Zarrabeitia L, Daroca G, Muñoz P, López-Hoyos M, Haya A, Martínez-Taboada VM (2017) Serological evolution in women with positive antiphospholipid antibodies. Semin Arthritis Rheum 47:397-402

31. Criado-García J, Fernández-Puebla RA, Jiménez LL, Velasco F, Santamaría M, Blanco-Molina A (2008) Anticoagulation treatment withdrawal in primary antiphospholipid syndrome when anticardiolipin antibodies become negative. Rev Clin Esp 208:135-137

32. Coloma-Bazán E, Donate-López C, Moreno-Lozano P, Cervera R, Espinosa G (2013) Discontinuation of anticoagulation or antiaggregation treatment may be safe in patients with primary antiphospholipid syndrome when antiphospholipid antibodies became persistently negative. Immunol Res 56:358-361

33. Meroni PL, Borghi MO, Raschi E, Tedesco F (2011) Pathogenesis of antiphospholipid syndrome: understanding the antibodies. Nat Rev Rheumatol 7:330-339

34. Rothwell PM, Cook NR, Gaziano JM, Price JF, Belch JFF, Roncaglioni MC et al (2018) Effects of aspirin on risks of vascular events and cancer according to bodyweight and dose: analysis of individual patient data from randomised trials. Lancet 392:387-399

35. Chauleur C, Galanaud JP, Alonso S, Cochery-Nouvellon E, Balducchi JP, Mare's P et al (2010) Observational study of pregnant women with a previous spontaneous abortion before the 10th gestation week with and without antiphospholipid antibodies. J Thromb Haemost 8:699-706

36. Soh MC, Pasupathy D, Gray G, Nelson-Piercy C (2013) Persistent antiphospholipid antibodies do not contribute to adverse pregnancy outcomes. Rheumatology (Oxford) 52:1642-1647

37. Empson M, Lassere M, Craig J, Scott JR (2005) Prevention of recurrent miscarriage for women with antiphospholipid antibody or lupus anticoagulant. Cochrane Database Syst Rev (2):CD00285

38. Clark CA, Laskin CA, Spitzer KA (2012) Anticardiolipin antibodies and recurrent early pregnancy loss: a century of equivocal evidence. Hum Reprod Update 18:474-484

39. Del Ross T, Ruffatti A, Visentin MS, Tonello M, Calligaro A, Favaro M et al (2013) Treatment of 139 pregnancies in antiphospholipid positive women not fulfilling criteria for antiphospholipid syndrome: a retrospective study. J Rheumatol 40:425-429

40. Amengual O, Fujita D, Ota E, Carmona L, Oku K, Sugiura-Ogasawara $\mathrm{M}$ et al (2015) Primary prophylaxis to prevent obstetric complications in asymptomatic women with antiphospholipid antibodies: a systematic review. Lupus 24:1135-1142

Publisher's Note Springer Nature remains neutral with regard to jurisdictional claims in published maps and institutional affiliations. 